\title{
Metropolis Parking Problems and Management Planning Solutions for Traffic Operation Effectiveness
}

\section{Yuejun Liu, Wuhong Wang, Chengxi Ding, Hongwei Guo, Weiwei Guo, Liya Yao, Hui Xiong, and Huachun Tan}

Department of Transportation Engineering, Beijing Institute of Technology, Beijing 100081, China

Correspondence should be addressed to Wuhong Wang, wangwuhong@bit.edu.cn

Received 18 July 2012; Accepted 26 September 2012

Academic Editor: Huimin Niu

Copyright (c) 2012 Yuejun Liu et al. This is an open access article distributed under the Creative Commons Attribution License, which permits unrestricted use, distribution, and reproduction in any medium, provided the original work is properly cited.

\begin{abstract}
Advances in mobility are clearly illustrated by the rapid development of urbanization and motorization in developing countries. Following the dramatic incensement of traffic demand, the parking problem has been becoming much more seriously important in many metropolises. With the aim of seeking solutions as to how the parking system could operate more efficiently by using new technologies and new methodologies, this paper discusses the application of geographic information system into the parking planning and management for traffic operation effectiveness in metropolis. The concentration of this paper includes the characteristics of parking demand and the causations of parking problems, especially the basic parking principle and strategies for solving parking problems from the perspective of geographic information system are discussed in enough detail in this paper.
\end{abstract}

\section{Introduction}

Nowadays, the parking problems have been one of the most discussed topics by the general public $[1,2]$. In many metropolises, the parking problems are becoming increasingly important. Following the rapid incensement of traffic demand, the imbalance between parking supply and parking demand has been considered as the main reason for metropolis parking problems. Moreover, the parking system plays a key role in the metropolitan traffic system, and the parking problems show closed relation with traffic congestion, traffic accident, and environment pollution.

The parking problems urge that the traffic professionals should seek more efficient solutions as to how the parking system could be used more efficiently and how parking 
planning and management could be improved by using new technologies and new methodologies. Recently, the geographic information system (GIS) has received considerable attention regarding its potential as a powerful technique for solutions of parking problems. GIS is best utilized for integration of various data sets to obtain homogeneous composite land development units which helps in identifying the problem areas and suggests conservation measures [3, 4]. GIS technology offers extremely significant power in transport modeling. The spread of GIS use facilitates the efficient and portable spatial data storage, updating, and processing [5]. In all transportation planning cases, the satisfaction of total travel demand must be balanced with the provision of reliable transportation services and with minimizing the costs of externalities associated with road traffic [6]. With the development of the Internet technology, the web-based GIS has an applications into transportation environmental analysis for planning and management [7], and the Web, Java, and CORBA technologies were explored in implementing GIS-T systems [8]. GIS is desirable in researches of vehicle parking planning which is closely related to geographical location [9].

The improvement of GIS technology opens a new way for urban parking planning and policy-making. With the aim of using GIS technology to improve the planning and management of parking, this paper discussed the metropolis parking problems and corresponding solutions. The characteristics of parking demand and the reasons for parking problems are investigated in detail. Then, the basic parking principle and strategies for solving parking problems are suggested with the application of GIS through a case study of Beijing.

\section{Key Issues of Parking Problems in Beijing}

The main reasons for parking problems in Beijing can be concluded as the disparity between the supply of parking facilities and parking demand. The parking demand is very urgent which can be explained as high speed of growth, high intension of using, and high density of gathering [10]. The key issues of parking problems in Beijing are discussed as the following.

The disparity between the rapid increment of motor vehicle and limited new parking facilities results the parking difficulty directly. Since 2004, the number of private cars in Beijing grows 0.34 million annually. On the other hand, the supply of new parking facilities (including curbside parking and off-road parking) increases 0.10 million each year, let alone the lack of parking left over by history. In Beijing, the sharp gap between demand and supply of parking spaces is widening year by year. Therefore, the parking problems seem to be more and more serious. It must be mentioned that the inefficiency of facility usage aggravates the parking problem. For the reasons involving with economic, zone bit, and the characteristics of drivers, some of the parking facilities are used frequently while some others are used infrequently. Taking the commercial centers Wangfujing and Xidan for example, it is common that $20 \%$ to $30 \%$ of the underground and public parking lots are vacant while the curb side parking spaces are occupied by $120 \%$ to $150 \%$ of the top limit it is designed. Unfortunately, more curb side parking spaces distribute in the bypasses and Hutong system, and the capacity in these roads reduces very sharply. A new vicious cycle of narrow road and occupying road space by curb parking begins.

The lack of professional parking management is another issue in parking problems [11]. At present in Beijing, irregular parking that violates the transportation rules will be fined of 200 Yuan with no deduction of transportation credit points. It's also well known that there is very low chance that irregular parking is fined. All in all, the cost for penalty 


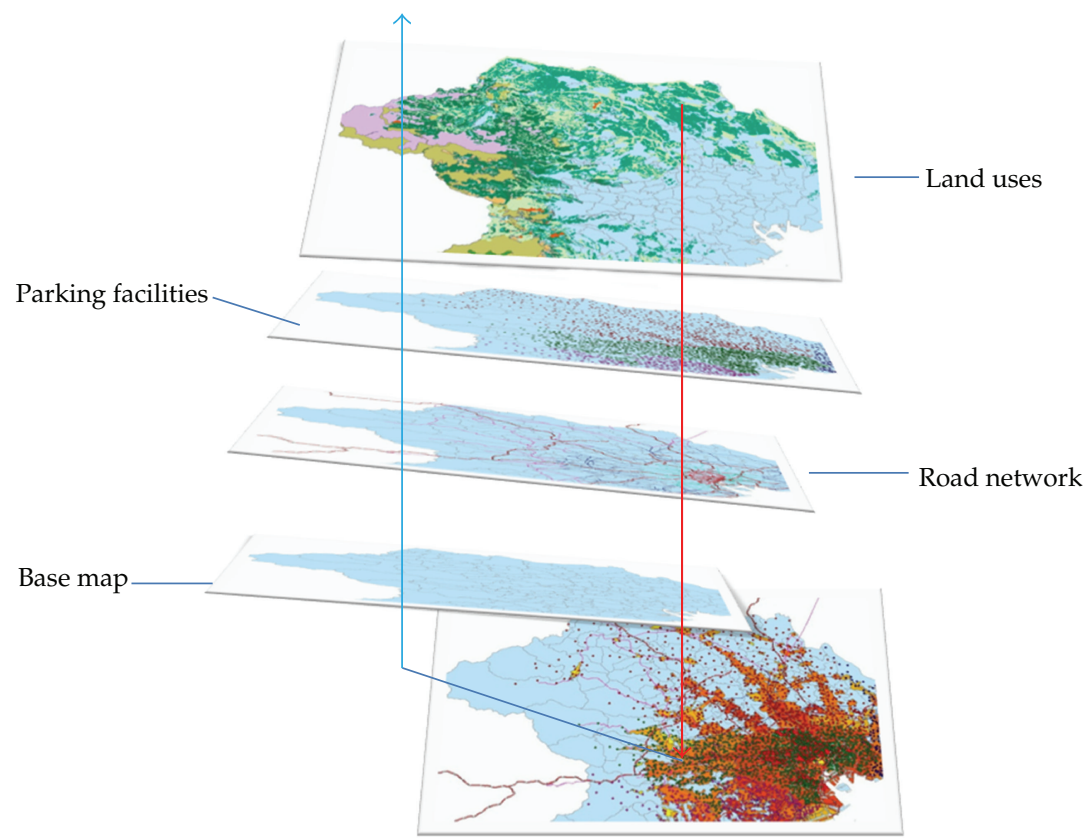

Figure 1: Map overlays.

of irregular parking is quite low and thus virtually increases the comparative opportunity cost. Comparatively in a metropolis such as those in Japan, irregular parking will be strictly punished and recorded. An interesting phenomenon is that the motor vehicles are used more intensive in Beijing, especially for the official car [12,13]. The intensive using of motor vehicles leads to high demand of parking spaces while it is an uneven distribution in space and demand. During the period of commuting time, a large part of cars are driven out from garages and need parking lots afterwards, and thus, the accumulated time for parking is comparatively long, that is, demand for parking stays at specific time intervals in the morning and afternoon whereas parking supply is evenly distributed all day. The more intensive traffic demand facing the nonprofessional parking management would make a turn for a worse.

\section{A Case Study for Parking Planning and Management}

On parking planning, the need for new parking facilities should best be considered with due regard to the existing nearby parking facilities. With the powerful features typical of a GIS, it will allow decision-makers to visualize the need for the new parking facilities in relation to the existing nearby parking facilities not just in terms of their availability, but also the proximity through examining the topological relationships. Through the ArcGIS software platform, we provided decision support for a project of parking management and facilities in a city (Figure 1). Parking facility management and parking planning process in GIS is as follows.

Step 1. to determine input datasets. In this case (Figure 2), the input data included road network layout, traffic zone layout, and survey data (e.g., parking duration, parking type) [14]. 


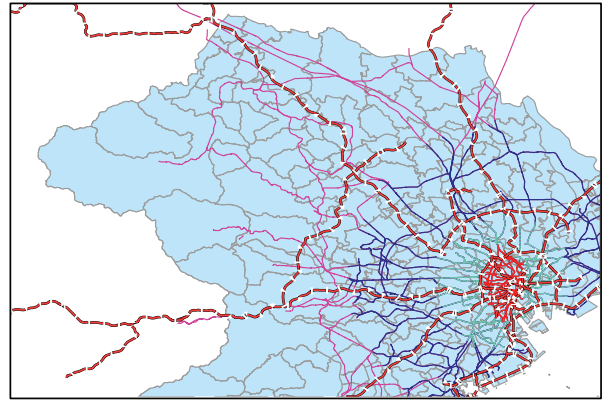

(a) Road network

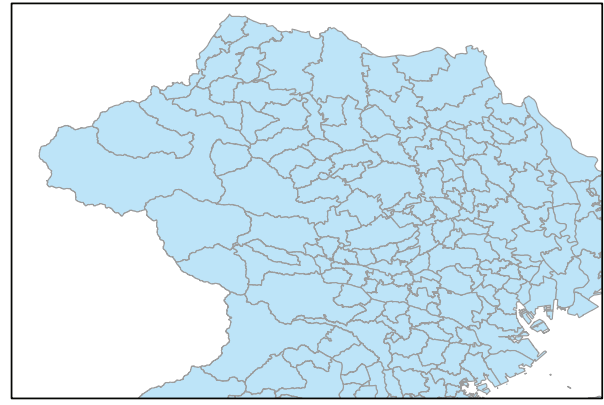

(b) Traffic zone

Figure 2: Basic datasets.

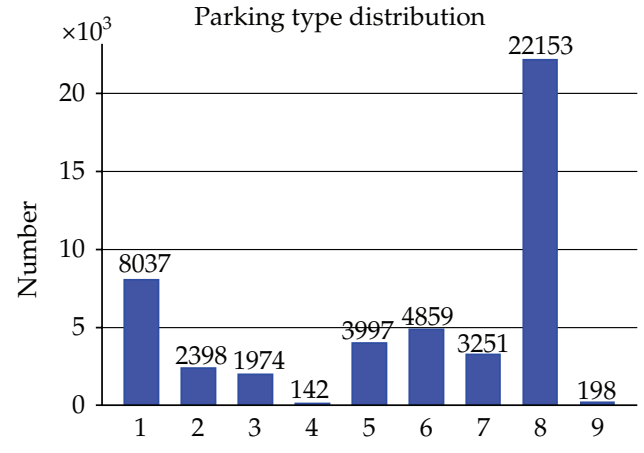

(a) Daytime

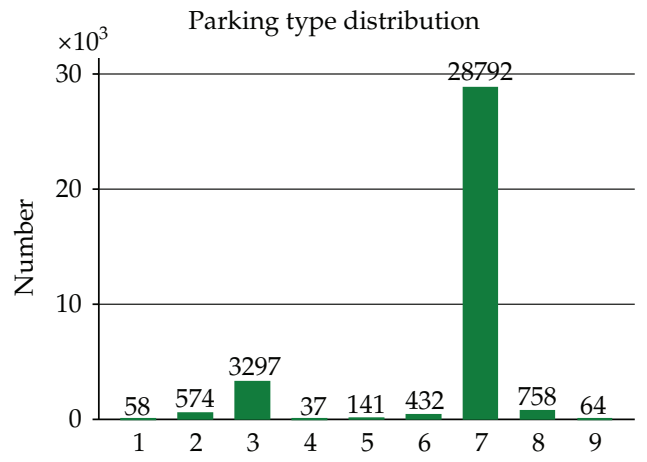

(b) Night time

Figure 3: The distribution of parking types.

Step 2. derived datasets. In this case, derived data sets include parking distribution, parking times, parking fee, parking category, and so forth. As an example, the parking type distribution is shown in Figure 3. In the figure, the numbers from 1 to 9 represent different parking types, such as road-side parking, public off-road parking lot, residential parking facilities, compound units, and temporary parking area [15].

Step 3. to reclassify datasets. The datasets are reclassified according to the existing parking facilities, the distribution of parking, the type, and so forth (Figure 4).

Step 4. to weight and combine the datasets. Through GIS spatial analysis, different weights are assigned to the datasets, so as to determine the parking areas with the most serious parking problems. Thus it can help to decide to plan and build parking facilities.

Figure 5 will be able to be very intuitive reflect the city's parking situation, as a result, it can provide decision support for making related policies and measures for parking problems and management. 


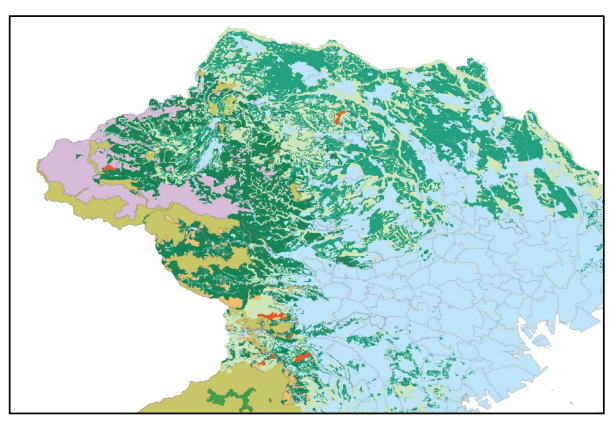

(a) Land uses

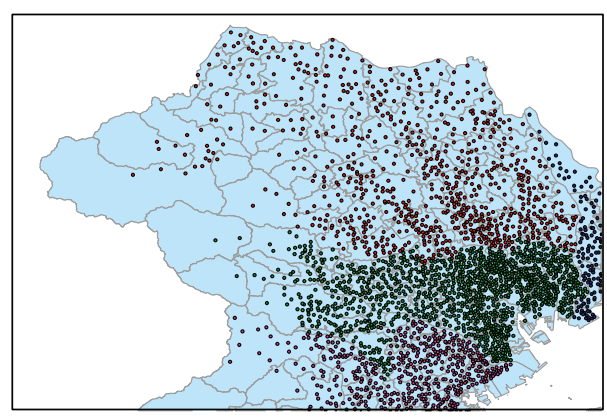

(b) Parking facilities

Figure 4: The existing parking facilities.

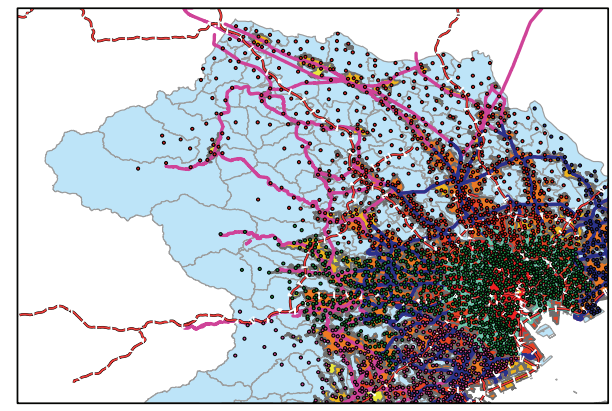

Figure 5: The distribution of parking problems.

\section{Conclusions}

Just like congestion, traffic accident, and environment pollution, the parking problems are the production of the urban urbanization and motorization; They are a concentrated expression of contradiction between car transitional needs and environmental conditions. New York, London, Tokyo, and other major cities in the process of urbanization, also face serious parking problems, which result in frequent and multiple traffic congestion and traffic accidents, and even gave a tremendous impact on the lives of the residents. Therefore, parking management is an important means of regulating motor process. To be aware of the parking problem is a reasonable solution to the parking problems, which makes technology and means of propaganda very necessary.

Even in the most efficient parking program, the communication is increasingly challenging. It is important for metropolis to communicate to the public that it is serious about regulations and enforcement. Booting and towing programs send the highly visible message to others that the metropolis is serious. The metropolis has to take booting and towing one step further through the use of the GIS application. The GIS web-based application data mines information stored in the parking management information system data warehouse to provide additional management insight. With GIS, a user can visually see characteristics, data, and information overlapping a base map. Through the features of GIS software, data comparisons can be made, trends can be identified, and action plans can be developed. 


\section{Acknowledgments}

This research was supported in part by the Programme of Introducing Talents of Discipline to Universities under Grant B12022 and National Natural Science Foundation of China under Grant 51010305084, 51110305060, 51210305046.

\section{References}

[1] T. K. Xia, M. Yang, R. Q. Yang, and C. Wang, “CyberC3: a prototype cybernetic transportation system for Urban applications," IEEE Transactions on Intelligent Transportation Systems, vol. 11, no. 1, pp. 142$152,2010$.

[2] W. Wang, Y. Mao, J. Jin et al., “Driver's various information process and multi-ruled decisionmaking mechanism: a fundamental of intelligent driving shaping model," International Journal of Computational Intelligence Systems, vol. 4, no. 3, pp. 297-305, 2011.

[3] J. N. A. Murthy, P. R. K. Reddy, B. Pateriya, and M. N. Kumar, "Integrated study for sustainable development using remote sensing and GIS techniques- a case study for part of Musicatchment, Rangareddy District, A. P.," in Remote Sensing Applications, Narosa Publishing House, 2001.

[4] G. Arampatzis, C. T. Kiranoudis, P. Scaloubacas, and D. Assimacopoulos, "A GIS-based decision support system for planning urban transportation policies," European Journal of Operational Research, vol. 152, no. 2, pp. 465-475, 2004.

[5] P. Ferrari, "A model of urban transport management," Transportation Research Part B, vol. 33, no. 1, pp. 43-61, 1999.

[6] P. D. Coddington, K. A. Hawick, and H. A. James, “Web-based access to distributed high-performance geographic information systems for decision support," in Proceedings of the 32nd Annual Hawaii International Conference on System Sciences, pp. 6015-6016, Maui, Hawaii, USA, January 1999.

[7] X. F. Li, S. R. Tu, X. F. He, and J. Ratcliff, "Web-based distribution of GIS metropolitan maps," in Proceedings of the 5th International Conference on Information Visualisation, pp. 419-424, London, England, 2001.

[8] J. P. Hu, J. G. Wei, and H. M. Wang, "Traffic planning based on GIS," Journal of the China Railway Society, vol. 4, no. 22, pp. 13-15, 2000.

[9] Beijing Transportation Research Center, "Beijing Transportation Development Annual Report," Beijing Transportation Research Center, Beijing, China, 2010.

[10] P. C. Box, “Curb-parking problems: overview," Journal of Transportation Engineering, vol. 130, no. 1, pp. $1-5,2004$

[11] X. P. Zheng and H. W. Li, "Countries around The World Face "stop hard"," Road Traffic Management, vol. 3, pp. 24-25, 2010.

[12] H. W. Guo, Z. Y. Gao, X. B. Yang, X. M. Zhao, and W. H. Wang, “Modeling travel time under influence of on-street parking," Journal of Transportation Engineering, vol. 138, no. 2, pp. 229-235, 2012.

[13] W. E. Marshall, N. W. Garrick, and G. Hansen, "Reassessing on-street parking," Transportation Research Record, no. 2046, pp. 45-52, 2008.

[14] D. Stevens, S. Dragicevic, and K. Rothley, “iCity: a GIS-CA modelling tool for urban planning and decision making," Environmental Modelling and Software, vol. 22, no. 6, pp. 761-773, 2007.

[15] G. Spadoni, D. Egidi, and S. Contini, "Through ARIPAR-GIS the quantified area risk analysis supports land-use planning activities," Journal of Hazardous Materials, vol. 71, no. 1-3, pp. 423-437, 2000. 


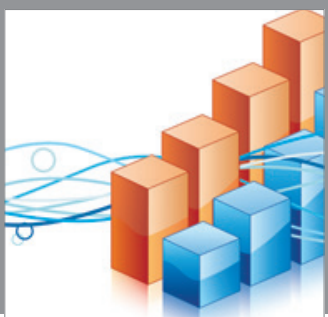

Advances in

Operations Research

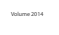

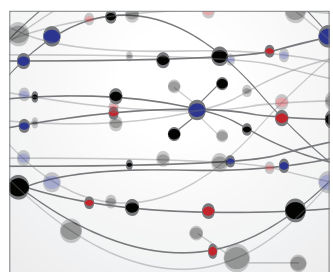

\section{The Scientific} World Journal
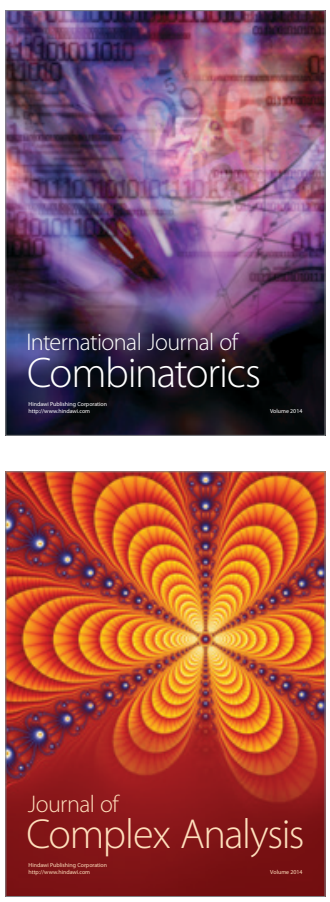

International Journal of

Mathematics and

Mathematical

Sciences
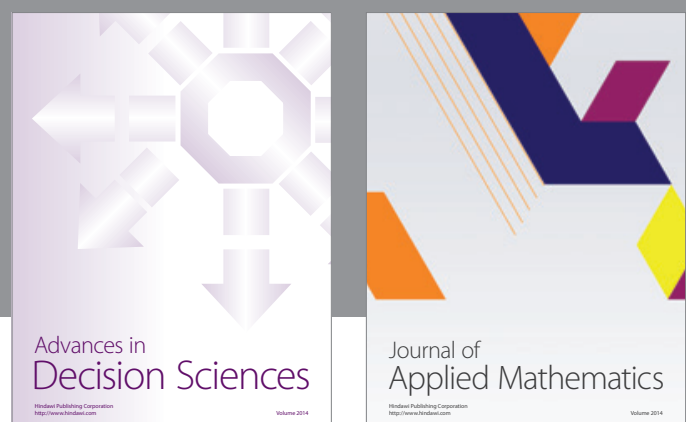

Journal of

Applied Mathematics
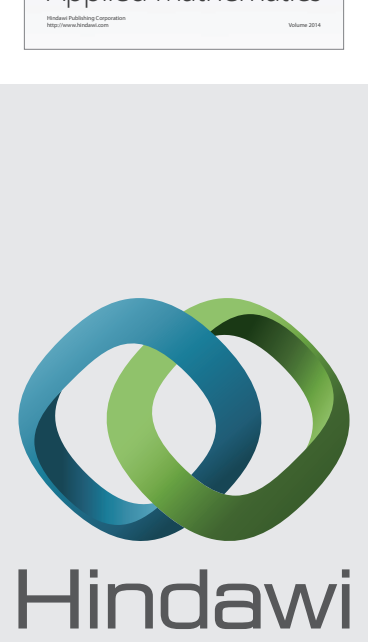

Submit your manuscripts at http://www.hindawi.com
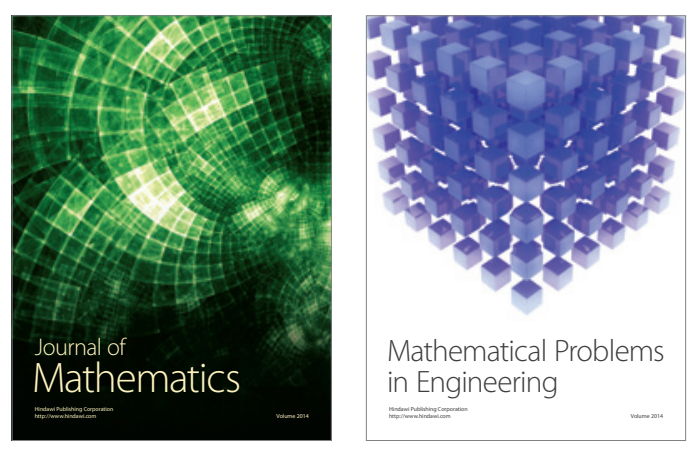

Mathematical Problems in Engineering
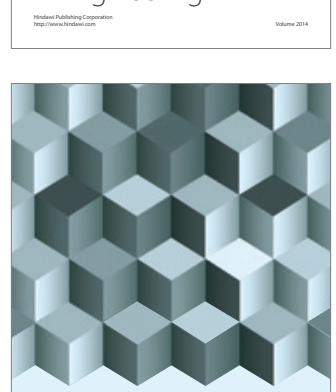

Journal of

Function Spaces
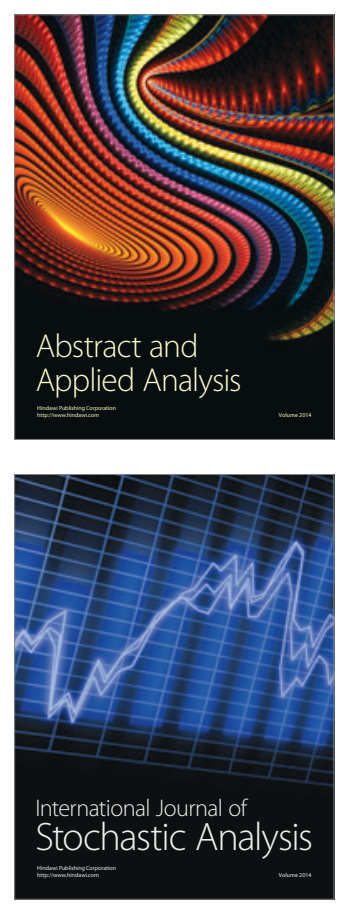

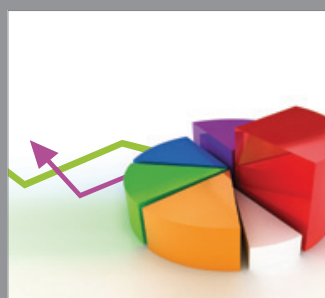

ournal of

Probability and Statistics

Promensencen
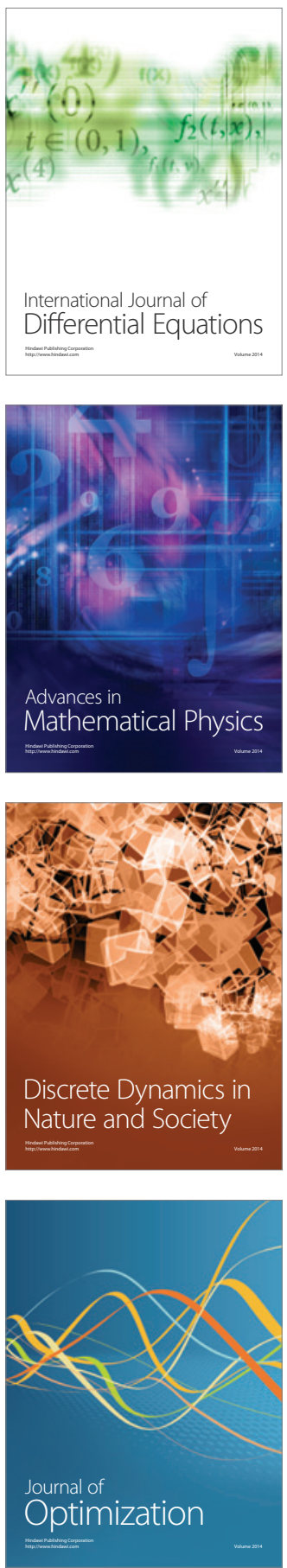